\title{
The main characteristics of atmospheric circulation associated with fog in Greece
}

\author{
E. E. Houssos, C. J. Lolis, and A. Bartzokas \\ Laboratory of Meteorology, Department of Physics, University of Ioannina, Greece \\ Received: 17 March 2009 - Revised: 3 October 2009 - Accepted: 14 October 2009 - Published: 12 November 2009
}

\begin{abstract}
The characteristics of the atmospheric circulation over Europe and the Mediterranean associated with the formation and the dissipation of fog in Greece are examined. The data used consists of: i) 3-hourly meteorological observations recorded at 16 meteorological stations in Greece and ii) daily (00:00 UTC) $2.5 \times 2.5$ grid point values of mean sea-level pressure, $500 \mathrm{hPa}$ geopotential height, $850 \mathrm{hPa}$ and $500 \mathrm{hPa}$ air temperatures and $1000-500 \mathrm{hPa}$ thickness over Europe for the period 1957-2002. 1055 fog events are extracted from the 3-hourly meteorological observations. A specific methodology scheme including S-mode Factor Analysis and k-means Cluster Analysis is applied to the grid point data sets for the first day of a fog event (D day), the day prior to D day (D-1 day) and the day that follows the last day of a fog event (END day) and the 1055 evolutions of the atmospheric circulation associated with fog events in Greece are classified into 10 clusters. The mean patterns of MSL Pressure, $850 \mathrm{hPa}$ and $500 \mathrm{hPa}$ air temperatures, 1000$500 \mathrm{hPa}$ thickness and $500 \mathrm{hPa}$ geopotential height show that in most of the clusters, the presence of anticyclonic conditions over the Balkans, a warm front passage, or a weak, humid southerly flow induced by the presence of a shallow depression over the western Mediterranean favor fog formation in Greece, while the dissipation of fog occurs when drier air masses are transferred over the Balkans. The main differences among the 10 clusters refer to the exact position, the intensity and the specific evolution of the surface and the upper air systems, the season of their predominance and the area of the Greek territory that mainly refer to.
\end{abstract}

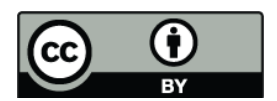

Correspondence to: E. E. Houssos (ehoussos@otenet.gr)

\section{Introduction}

Fog is a meteorological phenomenon that limits the horizontal visibility to less than $1 \mathrm{~km}$, due to the existence of water or ice droplets in the atmosphere near the ground. The droplets size ranges from $2 \mu \mathrm{m}$ to $65 \mu \mathrm{m}$ (Jiusto, 1981). They are formed when the water vapor condensates because of either a decrease in air temperature or an increase in absolute humidity. The low visibility induced by fog may cause major backups in transportation and may be responsible even for accidents.

Fogs can be classified in various types according to the mechanisms of their formation. Willett (1928) categorized fogs in two major types, advection fogs and radiation fogs. Advection fogs then were subdivided into those of warm air advection over cold surface (monsoon fog, sea fog, tropical air fog) and those of cold air advection over warm water surface (sea smoke, steam mist over lakes and rivers). On the other hand, radiation fogs are characterized by a marked temperature inversion near the surface due to the cooling of the boundary layer during cloudless nights. In the middle latitudes, where cyclonic circulation and front passages are common, front fogs are also frequent. These fogs are formed due to the mixing of nearly saturated air masses of different temperatures.

From the beginning of the previous century, the scientific community recognized the importance of the accurate temporal and spatial prediction of fog and many researchers studied the physical processes that take place in the air masses before and during such a phenomenon (see e.g. Taylor, 1917; Douglas, 1930; Lamb, 1943; Emmons and Montgomery, 1947). Fog is still studied in detail and many climatological studies have been carried out (see e.g. Cereceda and Schemenauer, 1991; Nakanishi, 2000; Friedlein, 2004; Tardif and Rasmussen, 2007), focusing on the seasonality, the duration, the frequency and other characteristics of fog in various areas of the earth. Also, many modern research

Published by Copernicus Publications on behalf of the European Geosciences Union. 
studies refer to the prediction of fog by using various approaches. Some approaches are based on mathematical models, which take into account the physical processes that are responsible for fog formation (see e.g. Guedalia and Bergot, 1994; Leipper, 1995; Bott, 2002), while some others are based on the identification of the circulation types that favor fog formation (see e.g. Meyer and Lala, 1990; Croft and Burton, 2005; Tardif, 2006).

For the Greek area, which is located in the eastern Mediterranean region, many efforts have been made in order to study and predict fog. For example, Kyriazopoulos and Livadas (1961) conducted a case study of steam fogs in the Greek seas. Angouridakis (1973) examined the connection between the occurrence of fog in Thessaloniki and the prevalence of certain weather types. Later on, Angouridakis and Flocas (1983) created a mathematical formula, which can be used in radiation fog prediction in the same region. Anthis and Cracknel (1999) using satellite data attempted to detect fog areas in central Greece and to predict the dissipation of fog. Finally, further work on fog occurrences in Thessaloniki has been done recently by Stolaki et al. (2008) and Houssos et al. (2008). In this study, a statistical approach, employing two multivariate methods, is followed, in order to identify the main characteristics of the atmospheric circulation that favor the formation of fog in Greece.

\section{Data and methodology}

Two data sets are used in the present study. The first one consists of 3-hourly meteorological observations recorded at 16 meteorological stations in Greece (Fig. 1), kindly provided by the Hellenic National Meteorological Service. The second one consists of daily (00:00 UTC) $2.5 \times 2.5$ grid point values of mean sea-level pressure, $500 \mathrm{hPa}$ geopotential height, $850 \mathrm{hPa}$ and $500 \mathrm{hPa}$ air temperature and $1000-500 \mathrm{hPa}$ thickness over Europe $\left(10^{\circ} \mathrm{W}-40^{\circ} \mathrm{E}\right.$ and $\left.30^{\circ}-60^{\circ} \mathrm{N}\right)$. Both data sets refer to the period 1957-2002 (ECMWF ERA40 Reanalysis Project).

A 24-h period from 12:00 UTC to 12:00 UTC of the next day is characterized as a fog day in Greece if in one or more of the 83 -hourly synoptic observations (15:00 UTC, 18:00 UTC, 21:00 UTC, ... 12:00 UTC) fog is reported for the present and/or the past weather ( $\mathrm{ww}=41$ to 49 and/or $\mathrm{W}=4$ ) at least at 2 meteorological stations. Isolated cases of fog in one station only are excluded since the basic aim of this work is to examine the role of the large-scale atmospheric circulation in the formation of fog and not the role of the local factors. The definition of the 24-h period from noon to noon was preferred in order to ensure, as much as possible, that a series of fog reports will not be split into two days as most of them take place during the night and early in the morning. The 00:00 UTC was selected for grid point data, as it is in the middle of the 24-h period defined (fog day).

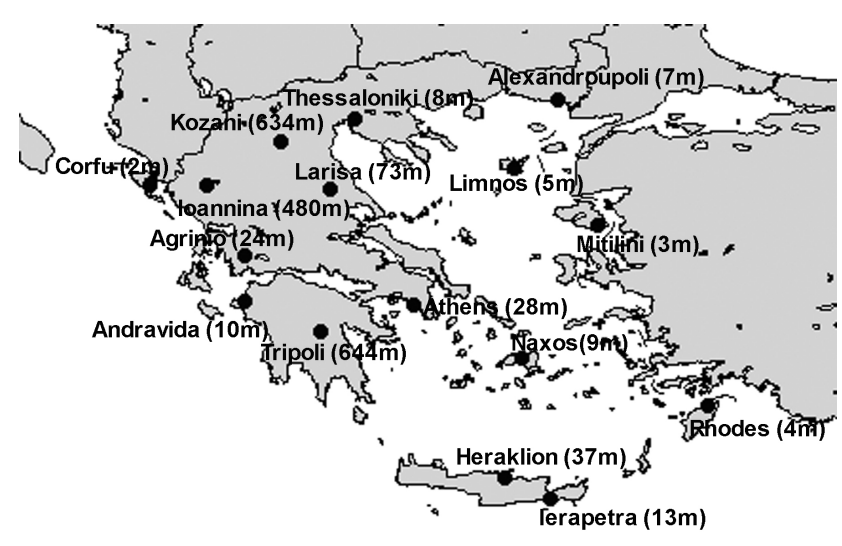

Fig. 1. The name, the location and the altitude $(\mathrm{m})$ of the 16 meteorological stations.

Any sequence of fog days is characterized as a fog event. A total of 1970 fog days and 1055 fog events are extracted from the first dataset. The first fog day of a fog event is characterized as D day, the 24-h period prior to D day is characterized as D-1 day and the 24-h period that follows the last fog day is characterized as END day. An analytic scheme of these definitions is presented in Fig. 2.

For the 1055 fog events, $51055 \times 273$ matrices consisting of the mean sea-level pressure, $850 \mathrm{hPa}$ air temperature, $1000-500 \mathrm{hPa}$ thickness, $500 \mathrm{hPa}$ air temperature and $500 \mathrm{hPa}$ geopotential height values respectively are constructed for each of D-1, D and END days. In these matrices the rows correspond to the 1055 fog events and the columns to the 273 grid points over Europe. The 5 matrices of each of D-1, D and END days are unified into one matrix. Thus, three $1055 \times 1365$ matrices are constructed, one for each of D-1, D and END days. Then, S-mode Factor Analysis is applied separately to each one of the three matrices in order to reduce their dimensionality. 10 factors are revealed for D-1 and D day data sets, while 11 factors are revealed for END day data set, accounting for at least $85 \%$ of the total variance in each case. Thus, three new matrices of factor scores are constructed $(1055 \times 10$ for D- 1 day, $1055 \times 10$ for $\mathrm{D}$ day and $1055 \times 11$ for END day). These three matrices are unified into one and each row then represents the evolution of the atmospheric circulation for a specific fog event.

$\mathrm{K}$-means Cluster Analysis is applied to the unified $1055 \times 31$ matrix of the factor scores and the 1055 evolutions of the atmospheric circulation associated with fog events in Greece are classified into 10 clusters. The number of clusters is decided by taking into account the "jump method" (Sugar and James, 2003). Finally, the mean 00:00 UTC patterns of $500 \mathrm{hPa}$ geopotential height, $850 \mathrm{hPa}$ air temperature and mean sea-level pressure are presented for each of the 10 clusters ( $500 \mathrm{hPa}$ air temperature and 1000-500 thickness patterns are not presented). The above patterns are constructed, by averaging the corresponding grid point values 


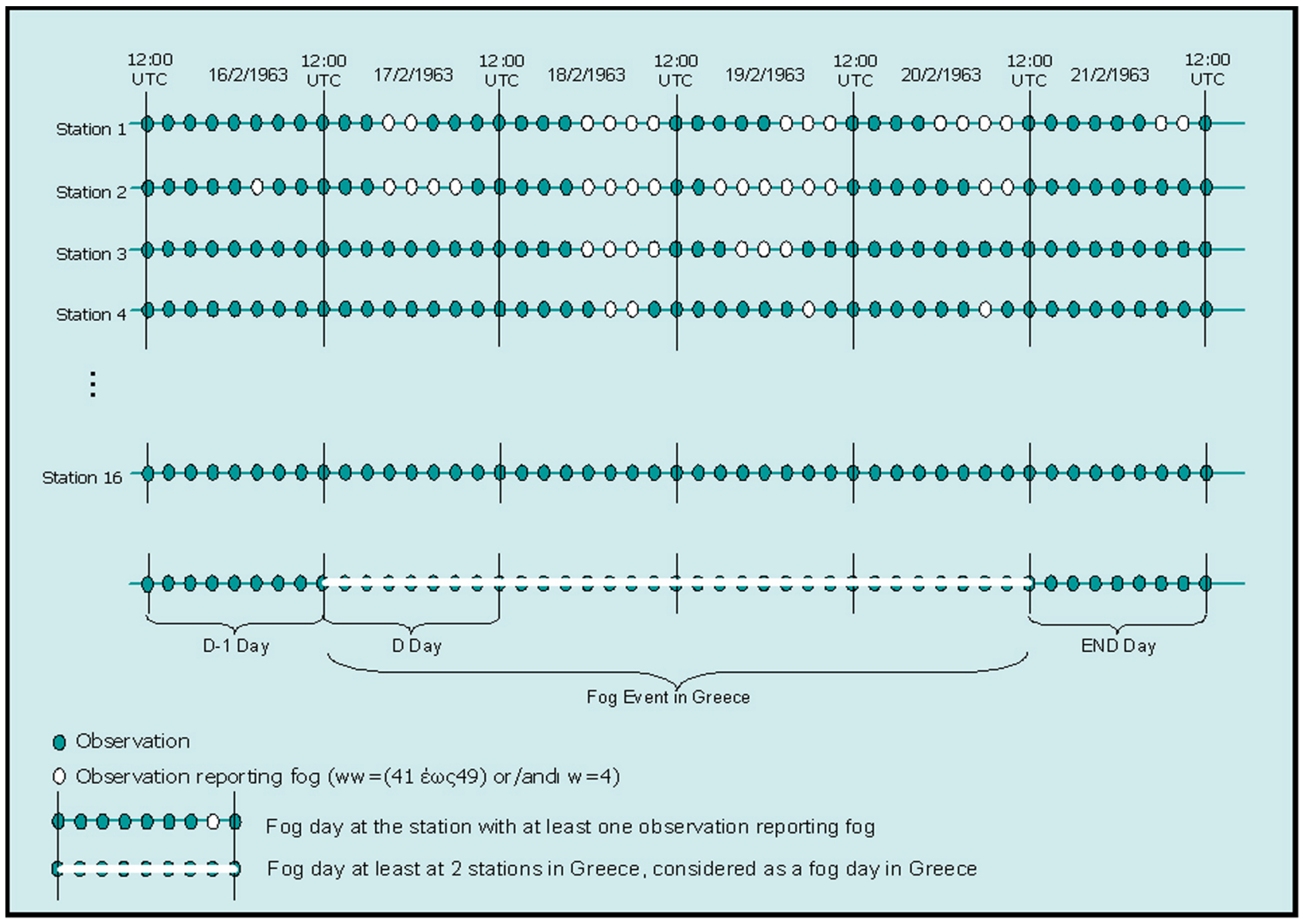

Fig. 2. A graphical representation of the definition of fog events in Greece.

for the days (D-1, D and END) classified to each of the 10 clusters. Also, the standard deviations of the corresponding grid point values are calculated for each cluster and for each day (D-1, D and END), as a measure of the variability of the mean patterns of the cluster.

\section{Results and discussion}

Prior to the presentation of the results, it has to be underlined that each cluster consists of the whole set of the 15 mean weather maps (only 9 mean weather maps are shown), which present the horizontal and the vertical structure and evolution of the atmospheric circulation associated with fog in Greece. Some striking characteristics of maps of a specific day or level, although they may play a very important role in the formation of a cluster, they present its features partially only.

For each mean weather map, the standard deviation of the presented parameter at each grid point is calculated. It is found that, for each parameter, the patterns of standard deviation for all clusters and days present a great similarity (figures not shown). For $500 \mathrm{hPa}$ height the standard deviation values appear increasing from south to north varying from
60-70 gpm over the Mediterranean to $100-120$ gpm over northern Europe. On the mean sea-level pressure maps the standard deviation values increase from southeast to northwest. Specifically, their values are around 3-4 hPa over the southeastern Mediterranean, $6 \mathrm{hPa}$ over the north Mediterranean and central Europe and up to $10 \mathrm{hPa}$ over northwestern Europe. The larger variability in the higher latitudes could be attributed to two reasons: (i) at higher latitudes the pressure systems are generally stronger than in the Mediterranean and therefore differences from case to case may be larger and (ii) as this study is focused on fog events in Greece, a specific Mediterranean pressure pattern causing fog in Greece, may be combined, in the same cluster, with pressure systems in higher latitudes centered in slightly different positions. Finally, for $850 \mathrm{hPa}$ temperature, the standard deviation values vary from $2^{\circ} \mathrm{C}$ over the Mediterranean and southwestern Europe to $3-4^{\circ} \mathrm{C}$ over central Europe and up to $6^{\circ} \mathrm{C}$ over western Asia, due to frequent influence of the Siberian cold air masses. 

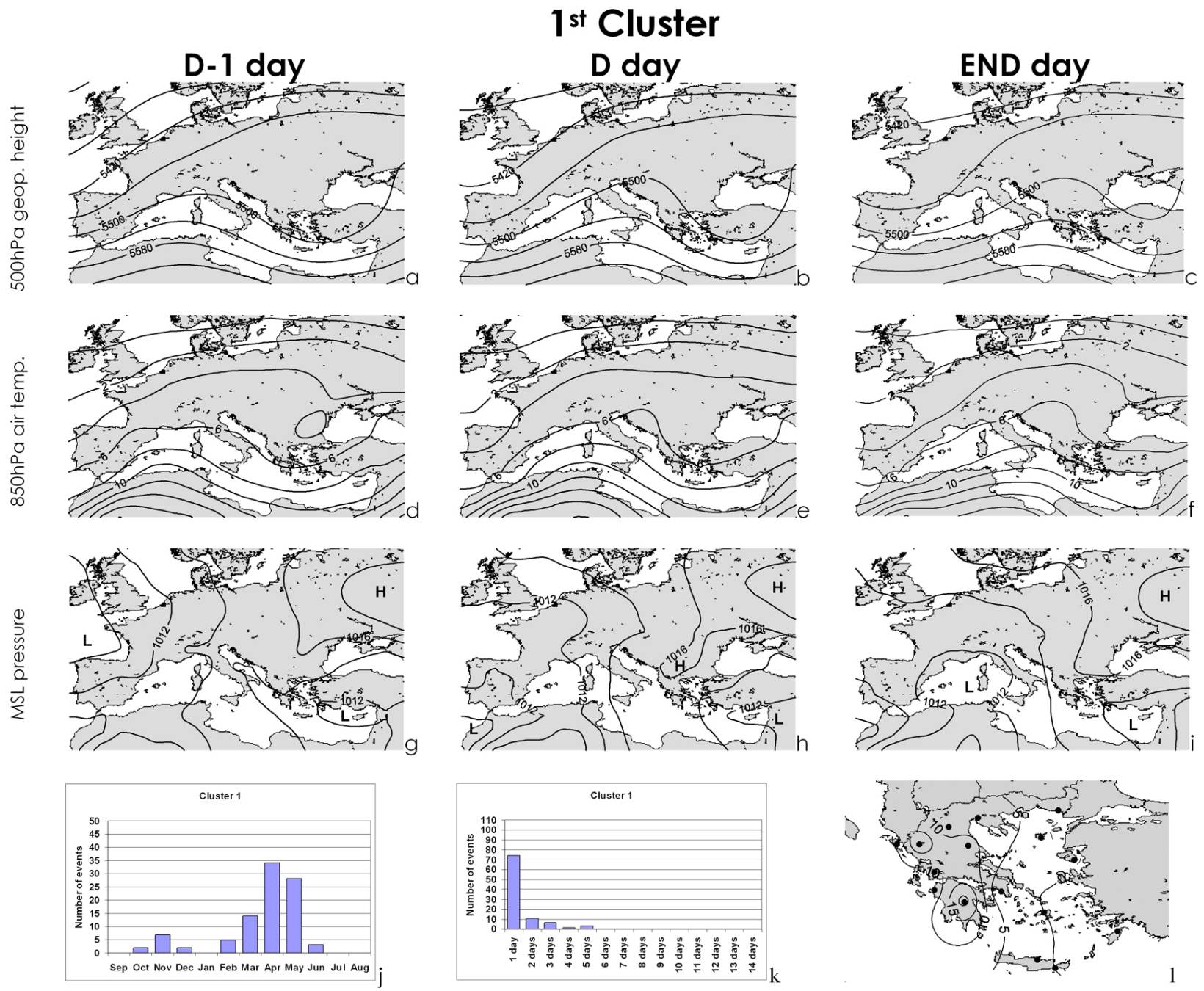

Fig. 3. Cluster 1: (a-i) Mean patterns of $500 \mathrm{hPa}$ geopotential height, $850 \mathrm{hPa}$ air temperature and Sea-level pressure for D-1, D and END days. (j) Intra-annual variation, (k) fog events duration and (l) percentage (\%) of fog days at each station for this cluster (dots indicate the location of the 16 meteorological stations).

Cluster 1 (95 fog events $-9 \%$ of all the events). One day before the formation of fog, an upper air ridge is apparent in the middle troposphere from Algeria to the Tyrrhenian Sea (Fig. 3a), causing a warm advection over the western Mediterranean (Fig. 3d). On the surface, a weak low pressure system over Cyprus is affecting southern Greece (Fig. 3g). On the first day of fog formation in Greece, the middle troposphere ridge has moved eastwards (Fig. 3b) and the warm advection is now more intense over the central Mediterranean and the western Balkans (Fig. 3e). On the surface, the low pressure system has also moved eastwards and as a result Greece is found in a barometric col between an anticyclone over southwestern Russia and a depression over Spain and Morocco (Fig. 3h). The lack of pressure gradient along with the warm advection favors fog formation. On the day after the dissipation of fog, a trough in the middle troposphere appears over the western Mediterranean (Fig. 3c), accompanied by a low pressure system on the surface (Fig. 3i), which intensifies the pressure gradient and the southerly flow over Greece. The frequency of fog events associated with the above conditions presents maximum in middle and late spring, while a secondary maximum is shown in November (Fig. 3j). The duration of these fog events rarely exceeds one day (Fig. 3k) and this seems logical, as the barometric col conditions usually do not last for long. The spatial distribution of the number of each station fog days divided by the total number of fog days (\%) classified in this cluster (Fig. 31), shows that stations in western mainland are mainly affected by this type of atmospheric circulation. 

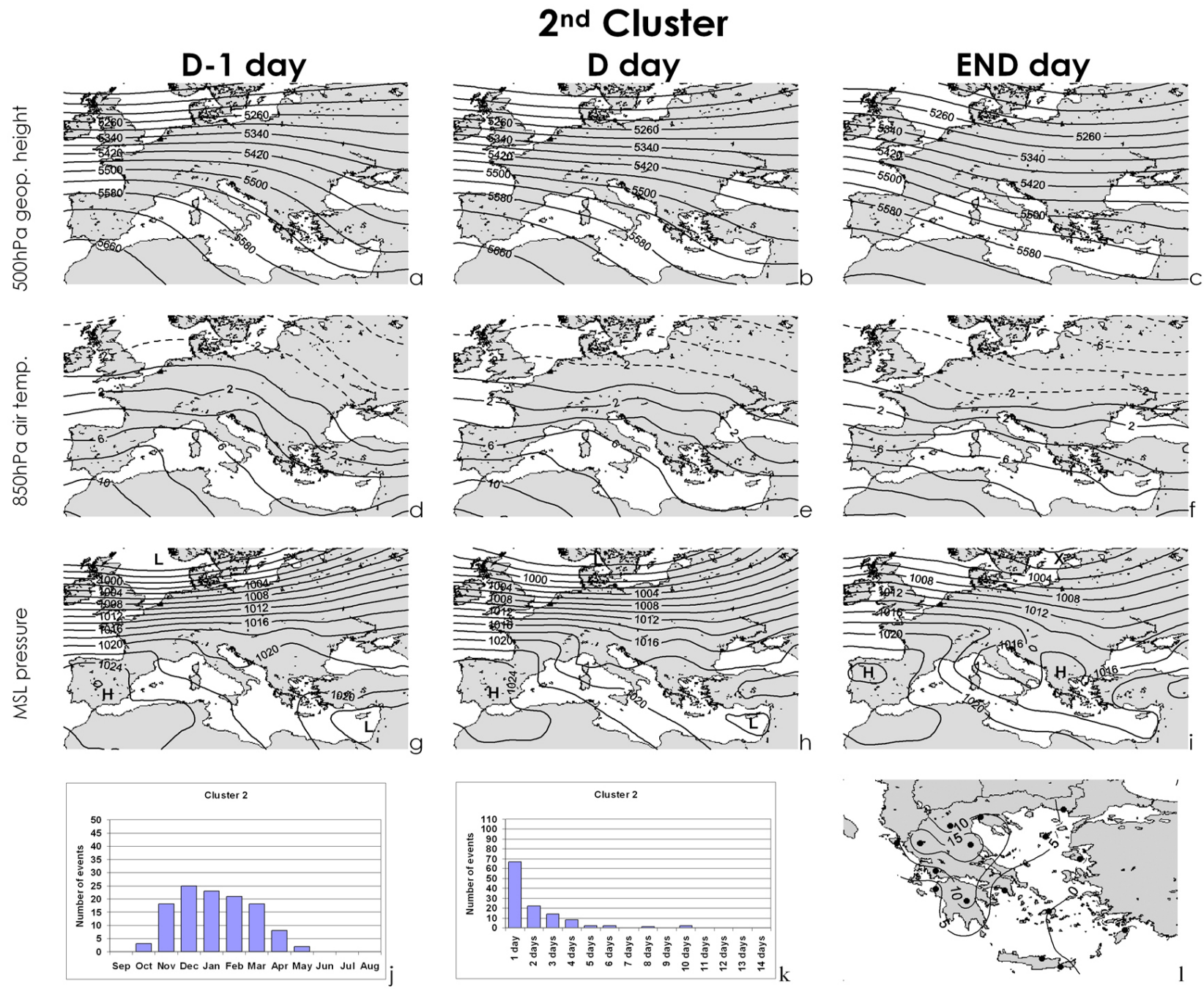

Fig. 4. As in Fig. 3, but for Cluster 2.

Cluster $2(118-11 \%)$. A deep low pressure system over northern Europe appears well developed in all the atmospheric levels during all the days of the events (Fig. 4a, b, $\mathrm{c}, \mathrm{g}, \mathrm{h}, \mathrm{i})$. This synoptic system causes an intense pressure gradient over northern and central Europe, associated with a strong zonal flow. On the contrary, in the Mediterranean the pressure gradient is very weak during D-1 and D day and, especially on D day, a constant pressure field, causing calm conditions, prevails over Greece (Fig. 4h). These conditions, along with a weak advection of warm and humid air masses from southwest, are responsible for the formation of fog on $\mathrm{D}$ day (Fig. 4e). These conditions occur mainly during winter (Fig. 4j) while the duration of the events is generally short (Fig. 4k).
Cluster 3 (93-9\%). On the surface, on D-1 day, a well developed anticyclone is located over the northern Balkans (Fig. 5g), tilting northwestwards with height (Fig. 5a), towards higher temperatures (Fig. 5d). On D day, the corresponding upper air ridge is moving eastwards covering continental Greece (Fig. 5b), causing subsidence, stability and fair weather conditions. On the same time, on the surface, the pressure gradient weakens (Fig. 5h) favoring radiation fog over continental Greece (Fig. 51). The advection of colder and drier air from northeast, which is shown on END day (Fig. 5f), is responsible for the dissipation of fog. These anticyclonic conditions are more common from November to January (Fig. 5j) and they present high persistence, as the duration of two and three days appears relatively frequent (Fig. 5k). 

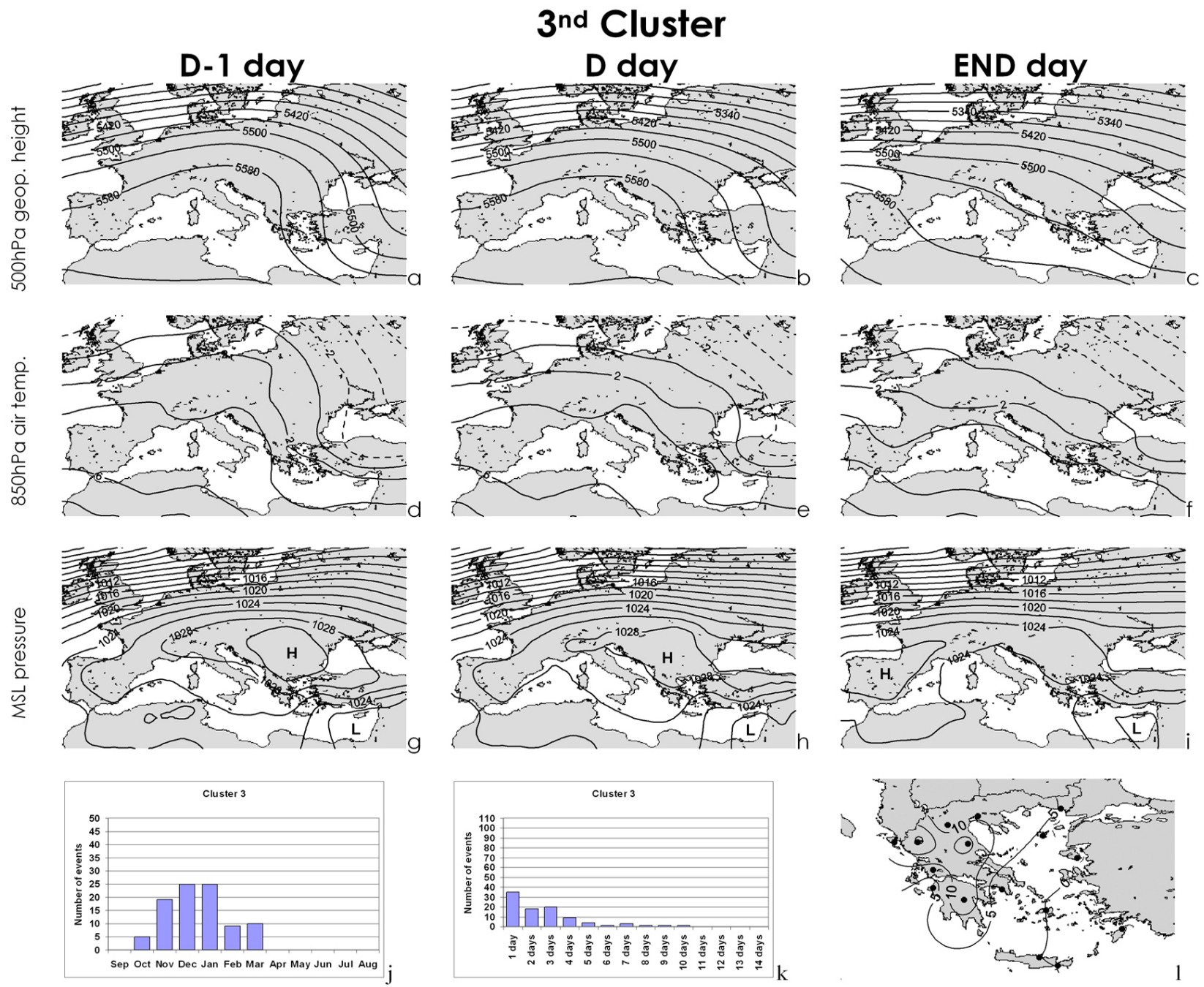

Fig. 5. As in Fig. 3, but for Cluster 3.

Cluster 4 (82-8\%). In the middle troposphere, on D-1 and $\mathrm{D}$ days, an anticyclonic circulation prevails over the western and central Mediterranean. On the surface, this circulation is related with an anticyclone over the Balkans with a weak pressure gradient (Fig. 6a, b, g, h). These synoptic conditions favor the formation of radiation fog in the area of central continental Greece (Fig. 61). On END day the anticyclone moves eastwards over the eastern Balkans and the Black Sea (Fig. 6c, i). In the same time, the approach of a depression from Italy (Fig. 6i) causes the intensification of the pressure gradient and the prevalence of a moderate southerly flow over Greece, conditions not favoring fog formation. The maximum frequency of this cluster appears in February-March (Fig. 6j). The duration is relatively short, as most of the events last for one day only (Fig. 6k).
Cluster 5 (81-8\%). On D-1 day the extended anticyclone over central Europe along with the cyclonic circulation over the western Mediterranean and northwestern Africa (Fig. $7 \mathrm{~g}$ ) cause an easterly flow over Greece. On D day the flow is weakened and the prevailing anticyclonic conditions over the Balkans (Fig. 7h) favor the formation of radiation fog over continental Greece (Fig. 71). On END day, the approach of a depression from southwest (Fig. 7i), results to the enhancement of the easterly flow and the arrival of cold and dry air masses (Fig. 7f), dissipating fog. The seasonal variability of the frequency of this cluster presents a primary maximum in November and a secondary maximum in March (Fig. 7j). The duration is relatively short, hardly exceeding 4 days (Fig. $7 \mathrm{k}$ ). 

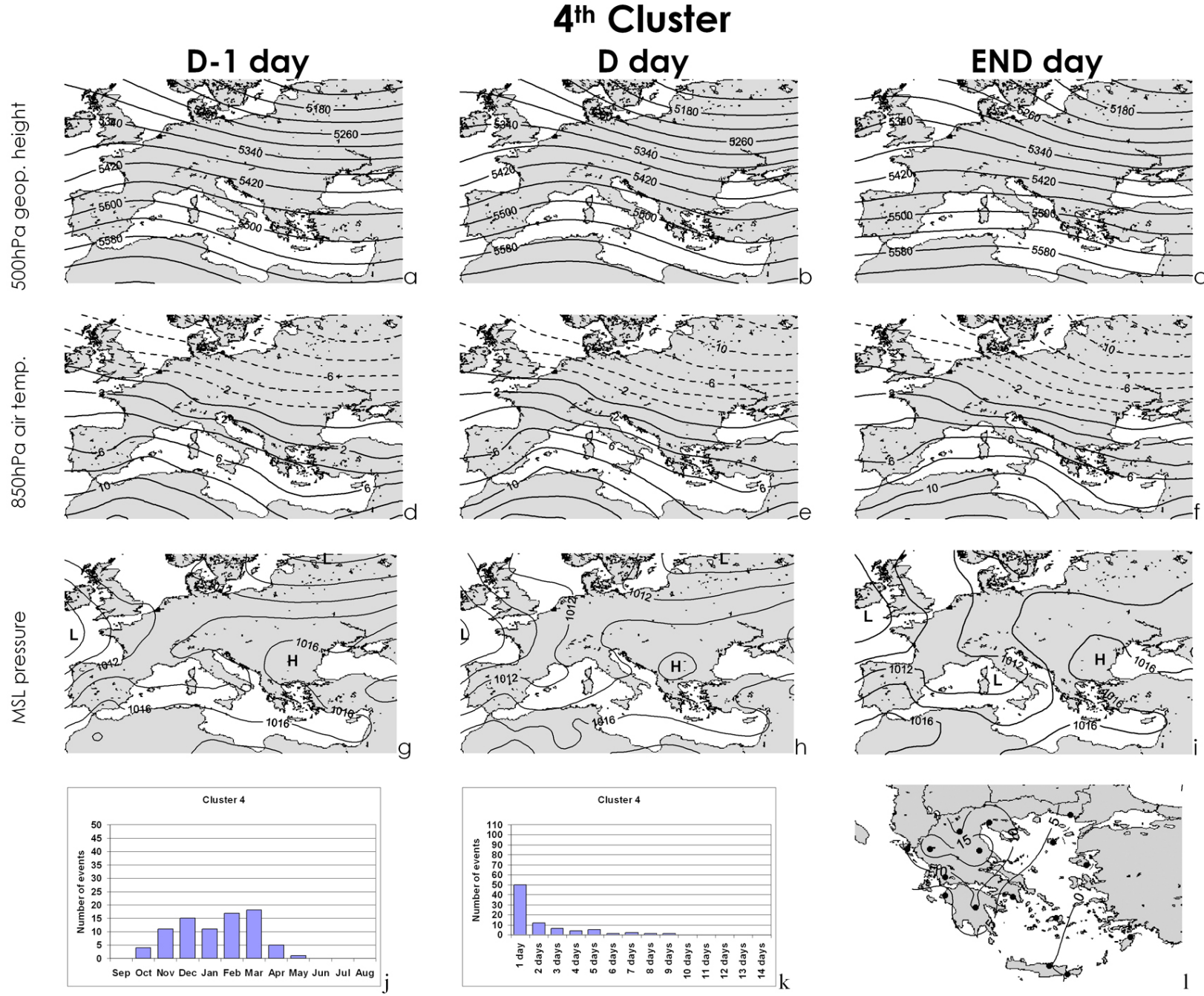

Fig. 6. As in Fig. 3, but for Cluster 4.

Cluster 6 (93-9\%). During D-1 Day, on the surface, the combination of a depression centered over the western Mediterranean and an anticyclone centered over western Russia (Fig. 8g), causes a moderate humid southeasterly flow over Greece. In the middle troposphere, the circulation over the central Mediterranean is almost zonal with its weak meridional component (Fig. 8a, b, c) being weakest on $\mathrm{D}$ day; conditions causing a north to south temperature gradient (Fig. 8e). The lack of a considerable southerly flow, in the surface (Fig. 8h), allows the formation of radiation fog, mainly in central and southern continental Greece (Fig. 81). Fog dissipates when the cyclonic circulation over the western Mediterranean is intensified in the whole vertical extent of the atmosphere (Fig. 8c, i), causing the enhancement of the southeasterly flow. The duration of fog events is short and they occur mainly during winter (Fig. 8j, k).
Cluster 7 (132-12\%). During D-1 day, the deep depression over Great Britain, which is well developed in all the atmospheric levels, causes a moderate to strong southwesterly flow over the western and the central Mediterranean (Fig. 9a, g). The air masses that are transferred to the northern Mediterranean coasts are humid, because of their passage over the sea. In Greece, this flow is weak, especially on D day (Fig. 9h) when fog formation is favored, in most parts of the mainland (Fig. 91). On END day cyclonic circulation is developed over the central Mediterranean (Fig. 9c, i) causing southwesterly flow and the cessation of the calm conditions which had favored fog. Fog events classified in this cluster occur mainly during late autumn and early winter (Fig. 9j). The duration of the events is high, relatively to the other clusters, as they may last even for 5 or 6 days (Fig. 9k). The latter may be due to the fact that such circulation patterns are generally characterized by high persistence. 

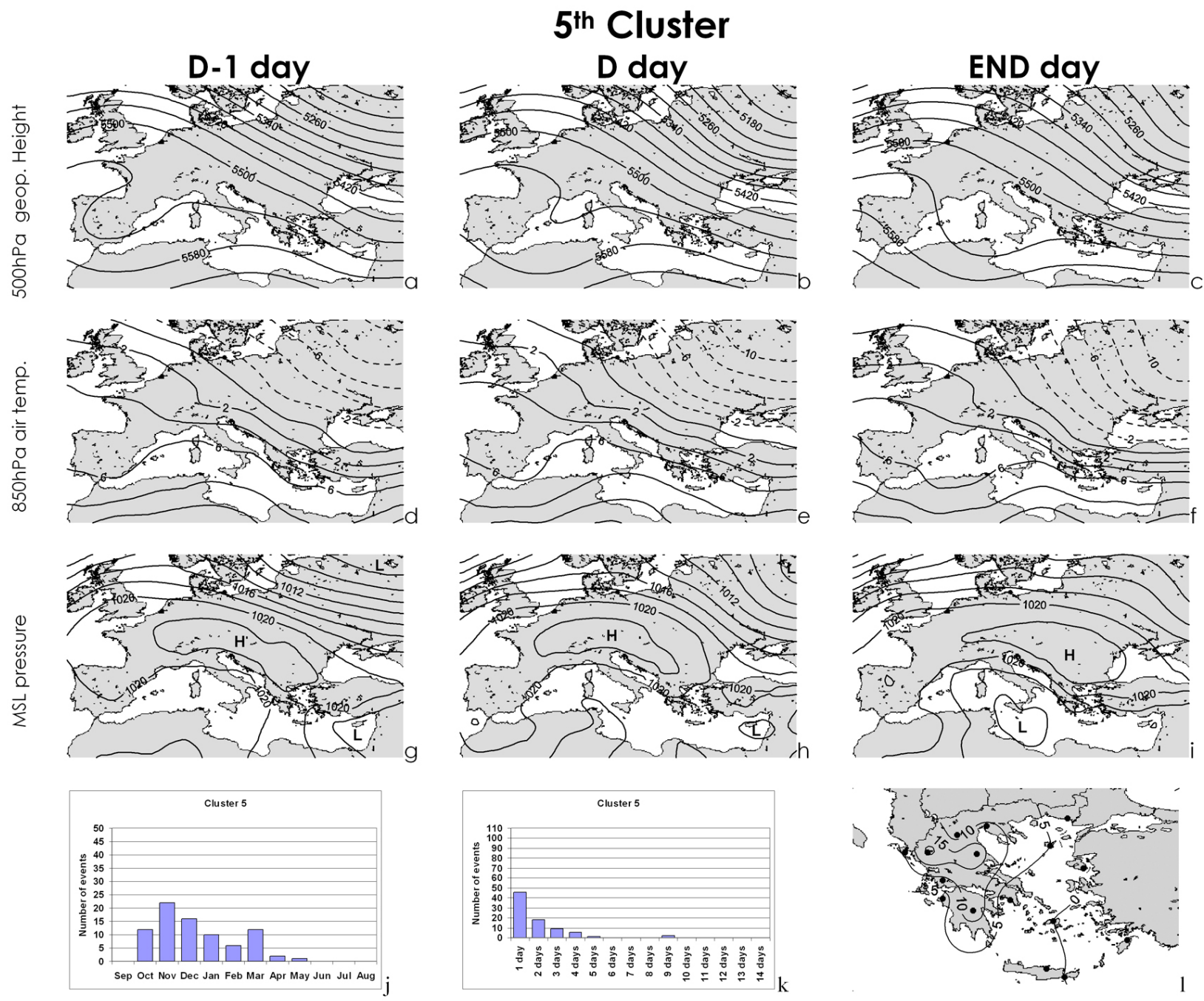

Fig. 7. As in Fig. 3, but for Cluster 5.

Cluster 8 (137-13\%). This cluster could be named as "warm season cluster" as there is a complete lack of events during the winter months (Fig. 10j). In the middle troposphere the circulation over southern Europe and the Mediterranean is almost zonal prior, and during the fog events (Fig. 10a-c) and the temperature gradient is oriented from north to south (Fig. 10d-f). This is not the case for the eastern Mediterranean where the atmospheric circulation is cyclonic in all the atmospheric levels. On D-1 day, the surface pressure gradient over the Balkans is relatively low (Fig. 10g), resulting to moderate to low wind speed. On $\mathrm{D}$ day, the pressure gradient over continental Greece seems to be further weakened (Fig. 10h), contributing to calm conditions, favoring fog formation especially during early autumn (Fig. 10j). In this season of the year, the duration of the night is longer relatively to the summer one, resulting to longer night cooling and thus to lower temperature and higher relative humidity values early in the morning. These events do not last for more than one day (Fig. 10k) and they mainly occur in the inland areas of western and southern Greece (Fig. 101), which are not so much affected by the north-northeasterly etesian winds that blow over the Aegean Sea during this season. 

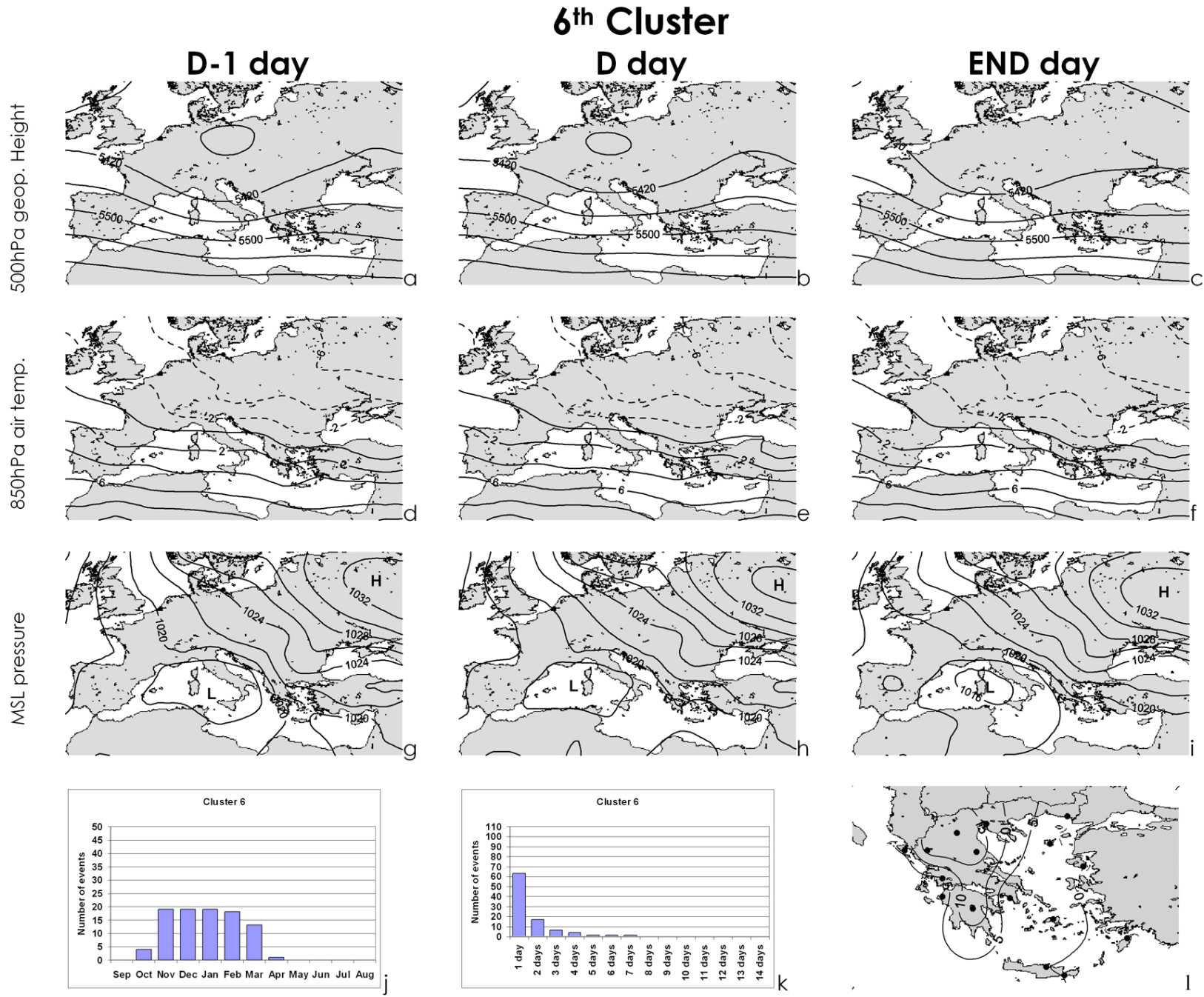

Fig. 8. As in Fig. 3, but for Cluster 6.

Cluster 9 (101-9\%). In the middle troposphere, an almost stationary trough is located over Italy and the Adriatic (Fig. 11a-c). In the lower troposphere, on D-1 day, a depression is located over Italy and the Ionian Sea (Fig. 11g). The warm sector of the depression affects Greece causing a southerly flow of warm and humid air masses over the country (Fig. 11d, e). On D day, the weakening of the southerly flow (Fig. 11h), along with the presence of the humid air masses, contribute to fog formation in continental Greece (Fig. 111). Fog dissipates, when the pressure gradient is enhanced again as a secondary depression is developed over the Aegean Sea (Fig. 11i) and dry cold air masses move over continental Greece (Fig. 11f). These fog events occur mainly in winter (Fig. 11j) and the majority of them last for one day (Fig. 11k).
Cluster 10 (123-12\%). On D-1 day, the cyclonic circulation in the middle troposphere over western Europe is associated with a surface low pressure system over the western Mediterranean. In the same time, the circulation over Asia Minor and the Black Sea is anticyclonic (Fig. 12a, g). These synoptic conditions result to a southerly flow of warm air masses over Greece (Fig. 12d), which are enriched with water vapor, because of their passage over the sea. During $\mathrm{D}$ day, the warm humid air masses pass over the cold land and the weakening of the wind (Fig. 12h) allows fog formation, especially over central Greece and the coastal areas of northern Aegean. On END day, fog dissipates as the trough and the corresponding depression approach Greece (Fig. 12c, i) worsening the weather conditions over the country. The frequency of fog events of this cluster presents a primary maximum in March and a secondary one in December (Fig. 12j). Their duration rarely exceeds 2 days (Fig. 12k). 



Fig. 9. As in Fig. 3, but for Cluster 7.

\section{Conclusions}

The general atmospheric circulation characteristics connected to fog formation and dissipation in Greece are examined. Ten types of specific atmospheric circulation structures over Europe are found. The basic mechanisms that contribute to fog formation is the surface night cooling associated with anticyclonic conditions and the advection of warm and humid air masses via a weak southerly flow. The main differences among the circulation types revealed are the exact position and the intensity of the synoptic systems and also their seasonality.

As the circulation types are derived from averaged data, only the general characteristics of the atmospheric circulation are revealed. The detailed dynamical processes associated with fog formation could be studied by examining some characteristic cases of fog events for each of the 10 clusters. The latter could be an object of a future research.
Acknowledgements. The present study has been supported by the PENED Programme 2003 for the support of research potential (Ministry of Development/GSRT - 3rd EU Framework Programme/Operational Programme of Competitiveness).

Edited by: S. Michaelides, K. Savvidou, and F. Tymvios Reviewed by: M. L. Martin and another anonymous referee 

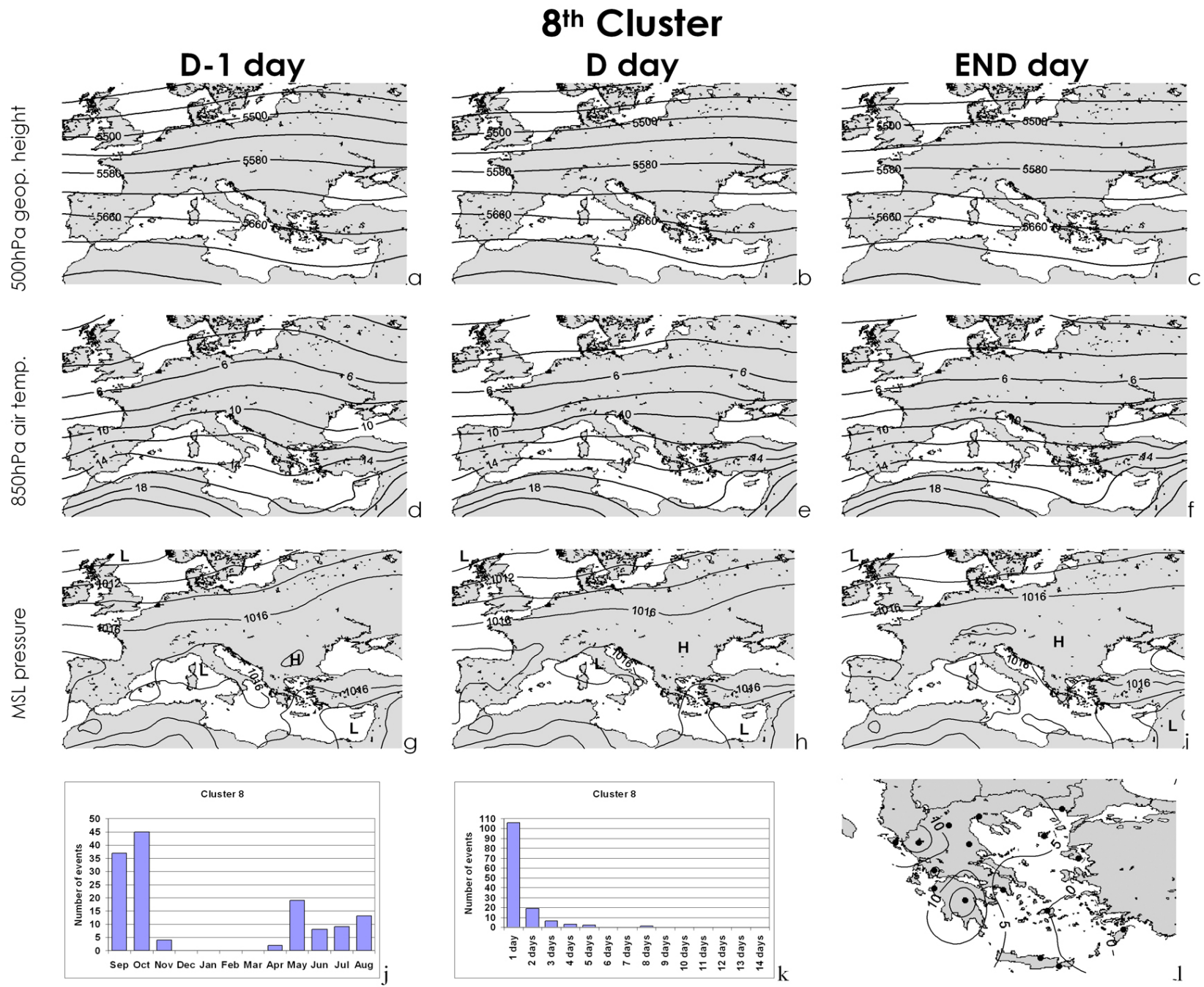

Fig. 10. As in Fig. 3, but for Cluster 8.

\section{References}

Angouridakis, V. E.: Fog and weather types in the area of Thessaloniki, Z. Meteorol., 23(7/8), 237-241, 1973.

Angouridakis, V. E. and Flocas, A. A.: Forecasting Radiation fog at Thessaloniki, Greece, Z. Meteorol., 33(3), 176-178, 1983.

Anthis, A. I. and Cracknell, A. P.: Use of satellite images for fog detection (AVHRR) and forecast of fog dissipation (METEOSAT) over lowland Thessalia, Hellas, Int. J. Remote Sens., 20(6), 1107-1124, 1999.

Bott, A.: PAFOG - A New Efficient Forecast Model of Radiation Fog and Low-Level Stratiform Clouds, Atmospheric Research, 2nd International Conference on Fog and Fog Collection, St Johns, Canada, 15-20 July 2001, 64, 191-203, 2002.

Cereceda, P. and Schemenauer, S. R.: The Occurrence of Fog in Chile, J. Appl. Meteorol., 30, 1097-1105, 1991.
Croft, P. J. and Burton, A. N.: Fog during the 2004-2005 winter season in the Northern Mid-Atlantic states: Spatial characteristics and behaviors as a function of synoptic weather types, Preprints, 12th Conference on Aviation, Range and Aerospace Meteorology, Atlanta, GA, 28 January-2 February 2006, P3.3, 2006.

Douglas, C.: Cold fogs over the sea, Meteorol. Mag., 65, 133-135, 1930.

Emmons, G. and Montgomery, R. B.: Notes on the physics of fog formation, J. Meteorol., 4, 206-206, 1947.

Friedlein, M. T.: Dense Fog Climatology Chicago O'Hare International Airport July 1996-April 2002, Bull. Am. Met. Soc., 515-517, 2004.

Guedalia, D. and Bergot, T.: Numerical Forecasting of Radiation Fog. Part II: A Comparison of Model Simulation with Several Observed Fog Events, Mon. Weather Rev., 122, 1231-1246, 1994. 

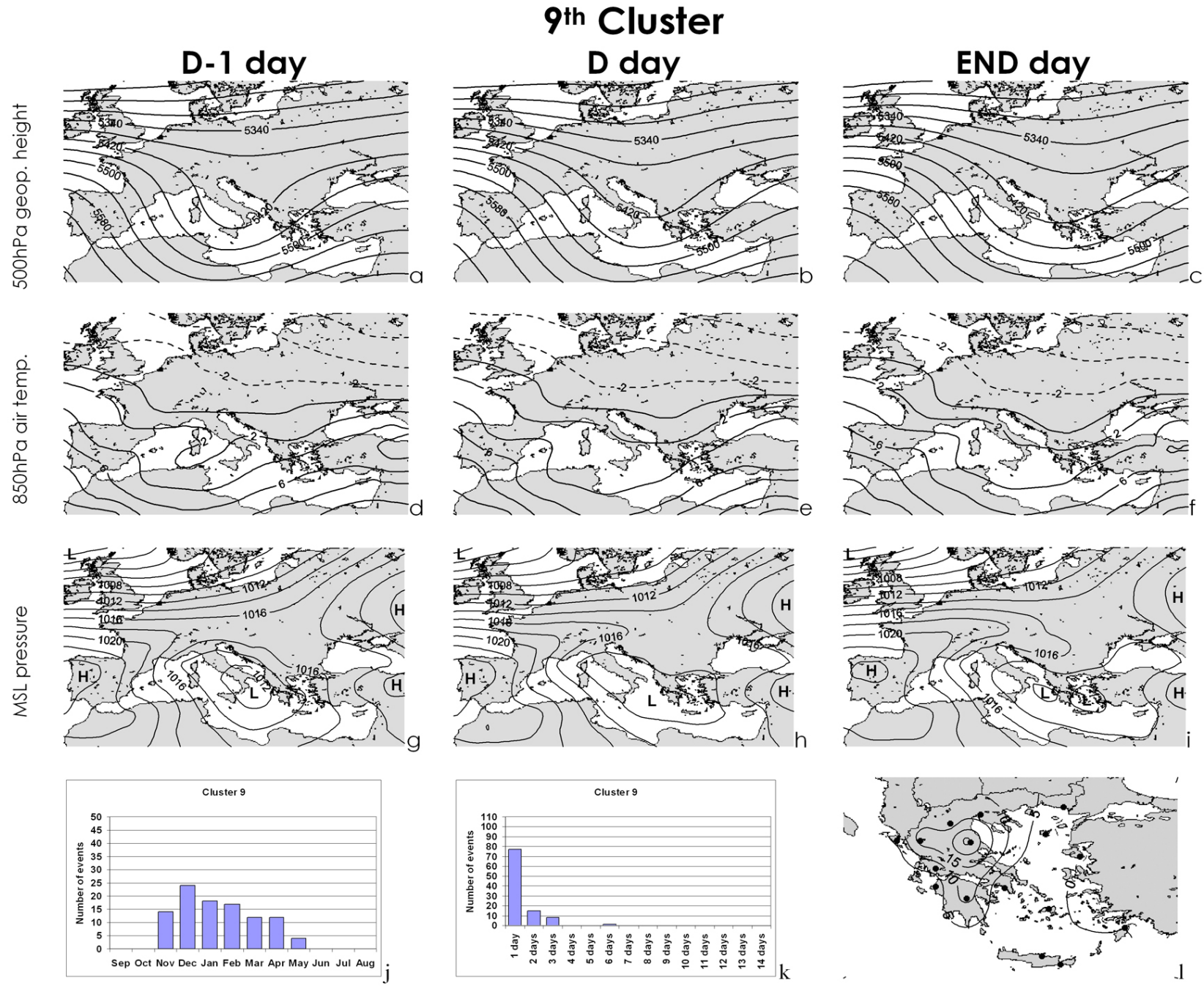

Fig. 11. As in Fig. 3, but for Cluster 9.

Houssos, E. E., Lolis, C. J., Charantonis, T., Ziakopoulos, D., and Bartzokas, A.: The main Synoptic Conditions Favouring the Formation of Fog in Thessaloniki, Proceedings of the 9th Hellenic Conference on Meteorology, Climatology and Atmospheric Physics, Thessaloniki, Greece, 28-31 May 2008, 561-568, 2008 (in Greek).

Jiusto, J. E.: Fog structure, Clouds, Their Formation, Optical Properties and Effect, edited by: Hobbs, P. V. and Deepak, A., Academic Press, 495 pp., 1981.

Kyriazopoulos, B. D. and Livadas, G. C.: Steam Fog in Greek Seas, Meteorologika, 7, Publications of the Meteorological Institute of the University of Thessaloniki, 88 pp., 1961.

Lamb, H.: Haars or North Sea Fogs on the coasts of Great Britain, Meteorology Office Publication M. O. 504, 24 pp., 1943.

Leipper, D. F.: Fog Forecasting Objectively in the California Coastal Area Using LIBS, Weather Forecast., 10, 741-762, 1995.

Meyer, M. B. and Lala, G. G.: Climatological aspects of Radiation
Fog Occurrence at Albany, New York, J. Climate, 3, 577-586, 1990.

Nakanishi, M.: Large-eddy simulation of radiation fog, Bound.Lay. Meteorol., 94(3), 461-493, 2000.

Stolaki, S., Kazadzis, S., Foris, D., and Karacostas, Th.: Study of fog occurences' characteristics at Thessalonini Airport, as a forecasting tool, 10th Plinius Conference on Mediterranean Storms, Nicosia, Cyprus, 22-24 September 2008, PLINIUS10-A-00084, 2008.

Sugar, A. C. and James, M. G.: Finding the Number of Clusters in a Dataset: An Information Theoretic Approach, J. Am. Stat. Assoc., 98, 750-763, 2003.

Tardif, R.: A Climatological Study of Low Ceiling and Fog Events Associated With the Occurrence of Precipitation in the Northeastern United States, 12th Conference on Aviation Range and Aerospace Meteorology, Atlanta, GA, 28 January-2 February 2006, 5.1, 2006. 

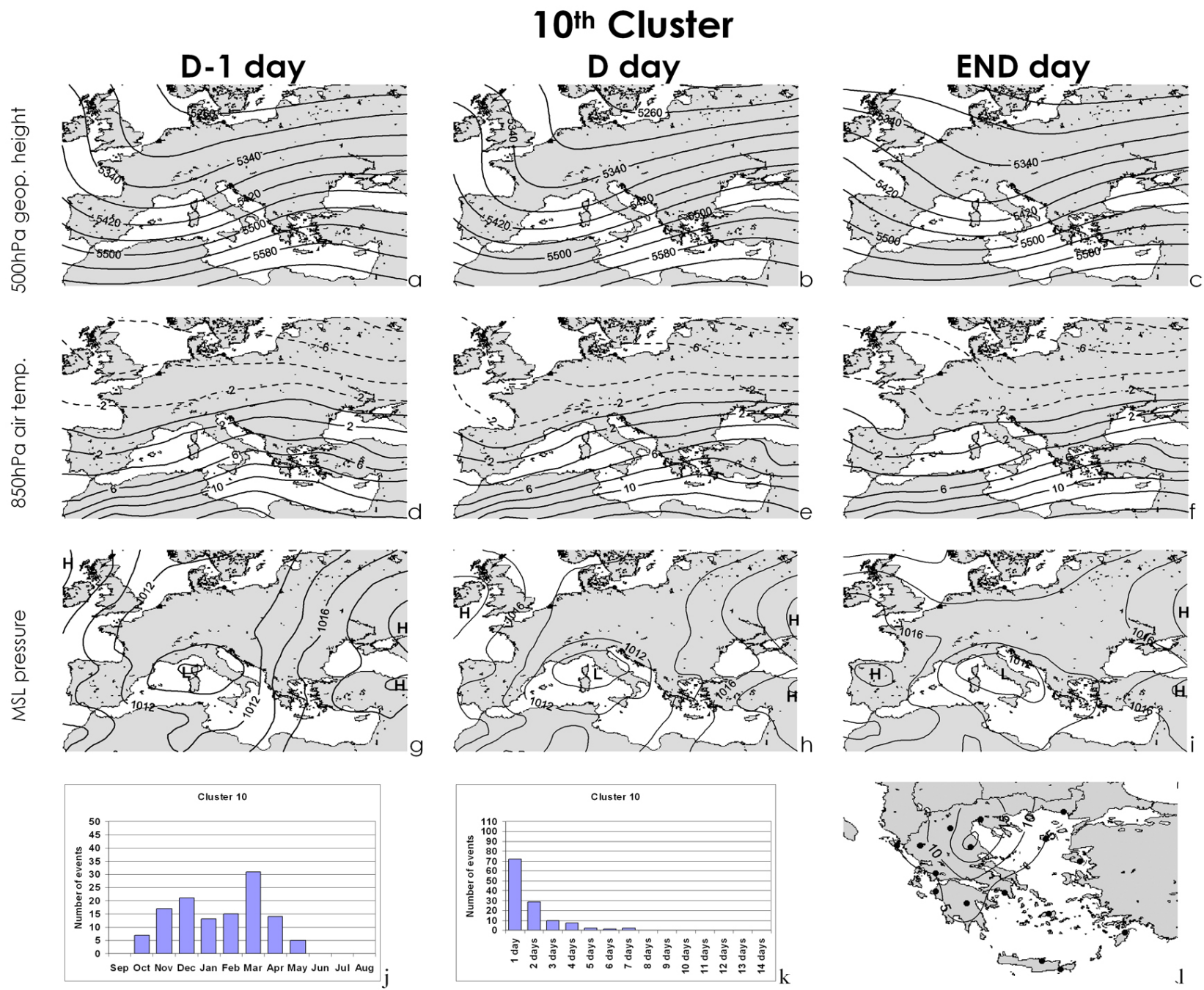

Fig. 12. As in Fig. 3, but for Cluster 10.

Tardif, R. and Rasmussen, M. R.: Event-Based Climatology and Typology of Fog in the New York City Region, J. Appl. Meteorol. Clim., 46(8), 1141-1168, 2007.

Taylor, G.: The formation of fog and mist, Q. J. Roy. Meteor. Soc., 43, 241-268, 1917.
Willett, C. H.: Fog and Haze, Their Causes, Distribution, and Forecasting, Mon. Weather Rev., 56(11), 435-468, 1928. 